\title{
Reactivation-dependent amnesia for appetitive memories is determined by the contingency of stimulus presentation
}

\author{
Jonathan L.C. Lee ${ }^{1}$ and Barry J. Everitt \\ Behavioural and Clinical Neuroscience Institute, Department of Experimental Psychology, University of Cambridge, \\ Cambridge CB2 3EB, United Kingdom
}

\begin{abstract}
Previously acquired aversive and appetitive memories are not stable and permanent. The reactivation of such memories by re-exposure to training stimuli renders them vulnerable to disruption by amnestic agents such as the noncompetitive $\mathrm{N}$-methyl-D-aspartate receptor antagonist (+)-5-methyl-10,11-dihydro-SH-dibenzo\{a,d\}cyclohepten-5,10imine maleate (MK-801). However, relatively little is known about the parameters that influence the reactivation process. Here, we show that the method of stimulus presentation during memory reactivation is of great importance. Male Lister Hooded rats were trained to acquire a lever press response that delivered a sucrose reward paired with a light conditioned stimulus (CS). The CS-sucrose association was then reactivated through re-exposure to the CS, either contingently upon the lever press response, or noncontingently in the absence of instrumental responding. Systemic administration of MK-801 $(0.1 \mathrm{mg} / \mathrm{kg})$ at the time of memory reactivation resulted in amnesia, and hence a reduction in subsequent sucrose seeking induced by, and dependent upon, presentation of the CS, only when the memory was reactivated contingently. Therefore, stimuli may have to be presented in the same manner at memory reactivation as during learning in order to render a previously acquired memory vulnerable to disruption. These results have important implications for the potential translational use of glutamatergic treatments in conjunction with targeted memory reactivation.
\end{abstract}

Memory reconsolidation is a process that is thought to occur following the reactivation or retrieval of a memory in order to re-stabilize that memory and enable its subsequent retrieval (Nader 2003; Dudai 2004). Thus, amnesia is observed when an amnestic agent is administered at the time of memory reactivation through re-exposure to salient training stimuli. Such reactivation-dependent amnesia has been demonstrated across several species and types of memory, and the mechanisms of the reconsolidation process have been investigated intensively (Alberini 2005). The resultant understanding of memory reconsolidation has led to the suggestion that disrupting the reconsolidation process may be effective as a treatment strategy for neuropsychiatric disorders in which persistent maladaptive memories play a prominent role, such as post-traumatic stress disorder (PTSD) and drug addiction (Lee et al. 2005; Debiec and Altemus 2006; Brunet et al. 2007).

More recently, attention has also been paid to the factors governing the initial reactivation of the memory. In particular, understanding the manner of stimulus presentation that is necessary to reactivate a consolidated memory successfully will be of great importance in the translational application of any reconsolidation-based treatment. It has been suggested that reexposure to directly relevant stimuli, rather than indirectly linked cues, may be of critical importance to reactivate a given memory (Debiec et al. 2006), and that at the pharmacological level, memory reactivation or "induction of lability" may involve signaling at NR2B-containing N-methyl- $D$-aspartate (NMDA) receptors (Ben Mamou et al. 2006). These studies employed an aversive fear conditioning procedure that is often used as a model of PTSD, in which rats are initially exposed passively to a previ-

\footnotetext{
'Corresponding author.
}

E-mail jlcl2@cam.ac.uk; fax 44-1223-333564.

Article is online at http://www.learnmem.org/cgi/doi/10.1101//m.976108. ously neutral stimulus paired with footshock, and the fear memory is subsequently reactivated and tested by passive reexposure to the stimulus. However, in appetitive tasks, including those used to model the compulsive drug seeking and taking characteristic of addiction, stimuli are often presented contingent upon an instrumental response during conditioning. Therefore, an important issue to resolve is whether reactivationdependent amnesia can be effected when the stimuli are presented both noncontingently, as in Pavlovian fear memory, or whether they must be presented contingent upon the instrumental response.

Our previous studies with cocaine self-administering rats suggest that the contingency of stimulus presentation at memory reactivation is unimportant (Lee et al. 2005, 2006a). However, these studies employed substantially different behavioral procedures to one another. Here, we used a procedure in which sucrose-seeking behavior depends on the conditioned reinforcing properties of a sucrose-associated conditioned stimulus (CS). We compared directly the efficacy of presenting a previously sucrosepaired stimulus either contingent upon an instrumental lever press response (as during training), or noncontingently in the absence of instrumental responding, in inducing reactivationdependent amnesia.

Male Lister Hooded rats, weighing 250-300 g, were restricted to $15 \mathrm{~g}$ food daily, and water was freely available throughout the experiment. All procedures were carried out in 12 operant chambers (Med Associates) as described previously (Hellemans et al. 2006), and were conducted in accordance with the United Kingdom 1986 Animals (Scientific Procedures) Act (Project License PPL 80/1767). During $10 \mathrm{~d}$ of training, the rats were placed individually in the operant chambers for $30 \mathrm{~min}$. The sessions began with illumination of the house light and extension of two levers into the chamber. A response on the active lever (left or right, counterbalanced) was reinforced by a 5-sec 
elevation of the liquid dipper (1.0 mL of $10 \%$ sucrose), accompanied by a 10 -sec illumination of the CS light above the lever, during which the house light was extinguished and both levers were retracted. On the final $2 \mathrm{~d}$ of training, rats were also habituated to the intraperitoneal injection procedure using the saline vehicle.

The CS-sucrose memory was reactivated on the third day after the final instrumental training session. For contingent memory reactivation, the rats were returned to the operant chambers and received a presentation of the 10-sec CS alone, following each active lever response, in a single 15-min session. No sucrose was available. Rats were injected with (+)-5-methyl10,11-dihydro-SH-dibenzo $\{\mathrm{a}, \mathrm{d}\}$ cyclohepten-5,10-imine maleate (MK-801) hydrogen maleate $(1 \mathrm{~mL} / \mathrm{kg}$; Sigma) or the saline vehicle, either 30 min before the start of the reactivation session, or immediately following its termination. The dose of MK-801 (0.1 $\mathrm{mg} / \mathrm{kg}$ ) has previously been shown to impair the reconsolidation of both aversive and appetitive pavlovian memories (Lee et al. 2006b; Lee and Everitt 2008).

Administration of MK-801 prior to, but not following, response contingent memory reactivation reduced subsequent cueinduced sucrose seeking (Fig. 1A). To test the ability of the CS to maintain and enhance responding in the absence of sucrose, the two levers were extended into the chamber for a 60-min session conducted $3 \mathrm{~d}$ after memory reactivation. Responding on the active lever was reinforced by a 1 -sec presentation of the CS, but not sucrose, during which the house light was extinguished but

\section{A Contingent reactivation}
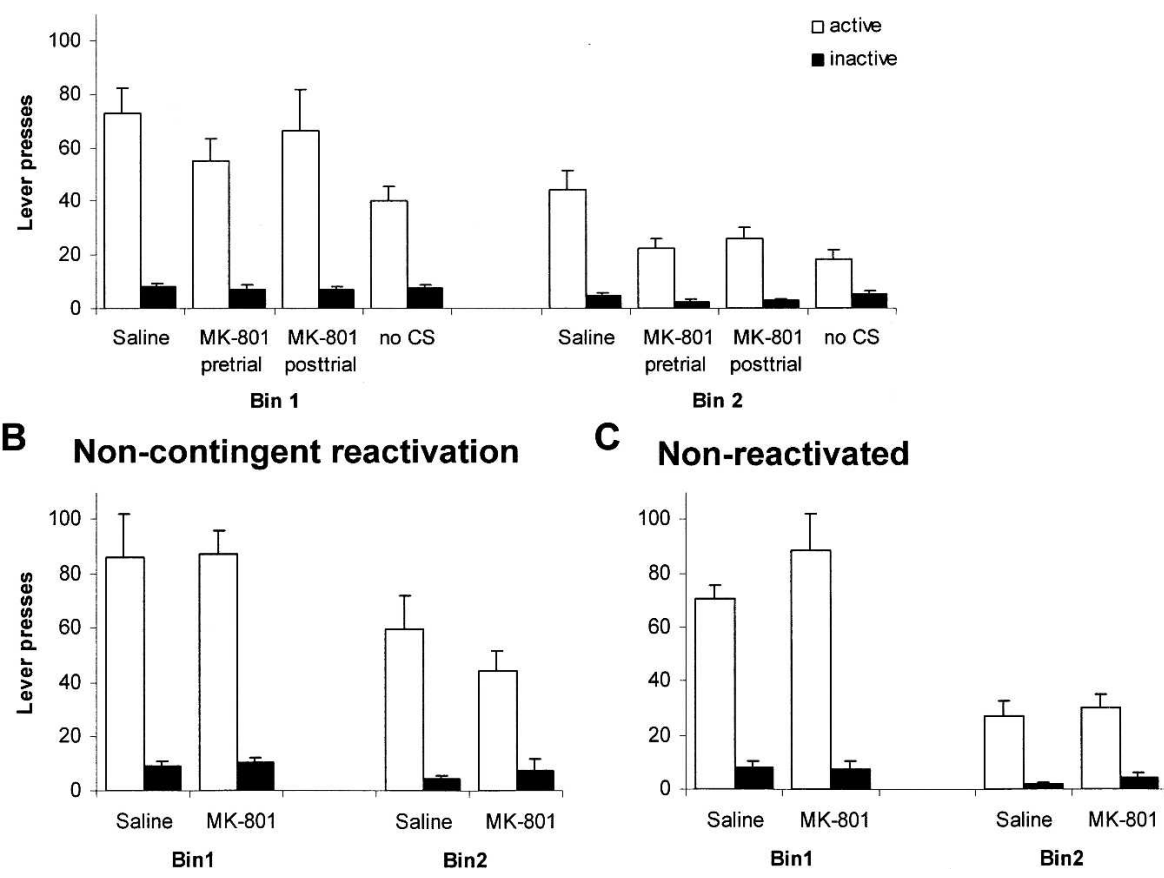

Figure 1. MK-801 administered prior to, but not immediately after, memory reactivation impaired subsequent cue-induced sucrose seeking. Active and inactive lever presses during the two 30-min bins of the test session were compared for contingently reactivated $(A)$, noncontingently reactivated $(B)$, and nonreactivated $(C)$ conditions. MK-801 administered prior to contingent memory reactivation resulted in a reactivation-dependent impairment in subsequent cue-induced sucrose seeking across the whole session (ANOVA; Lever $\times$ Reactivation $\times$ Treatment: $F_{(1,26)}=4.78, P<0.04$; Lever $\times$ Treatment: $F<1$; Lever $\times$ Reactivation $\times$ Treatment $\times$ Bin: $F<1)$. In contrast, there was no significant effect of MK-801 when administered either immediately after contingent memory reactivation (Lever $\times$ Reactivation $\times$ Treatment: $F_{(1,26)}=1.88, P>0.18$; Lever $\times$ Treatment: $F<1$; Lever $\times$ Reactivation $\times$ Treatment $\times$ Bin: $F<1$ ) or prior to noncontingent re-exposure to the $C S$ (Lever $\times$ Reactivation $\times$ Treatment: $F_{(1,21)}=1.38, P>0.25$; Lever $\times$ Treatment: $F<1$; Lever $\times$ Reactivation $\times$ Treatment $\times$ Bin: $F<1)$. Data presented as mean + SEM. the levers remained extended. Saline-injected rats responded at high levels on the previously active lever during the relapse test, whereas rats injected with MK-801 pre-trial responded at signifier levels. MK-801 administered immediately following reactivation resulted in intermediate levels of responding, ough importantly not different from saline-injected controls. memory reconsolidation is consistent with that obre 2008), and is indicative of a limited time period during which NMDA receptor signaling is necessary for appetitive memory re-

citically dependent upon the memory reactivation session, the omission of which resulted in MK-801-treated rats responding at levels no different from saline-administered controls (Fig. 1C). In contrast, when the rats were re-exposed to the CS in a response injection upon subsequent cue-induced sucrose seeking (Fig. 1B) moncontingent memory reactivation was conducted in presence of either the levers or sucrose.

When compared with a group trained and reactivated contingently under saline treatment, but tested in the absence of the CS (no CS), the control group administered with saline at the time of contingent memory reactivation responded at significantly higher levels $\left(F_{(1,14)}=14.52, P<0.01\right)$, thus demonstrating the ability of the pavlovian CS to maintain and enhance instrumental responding in the absence of sucrose. In contrast, there was only a trend toward greater responding in the group injected with MK-801 prior to contingent CS reexposure $\left(F_{(1,14)}=4.26, P=0.058\right)$. Therefore, statistically there was no difference between the effects of MK-801 injected prior to contingent memory reactivation and omission of the CS altogether at the test. However, it remains unclear whether the MK-801-induced deficit reflects a complete blockade of cue-induced sucrose seeking measured several days after the reactivation treatment session.

There were no differences between the groups during training. All groups acquired the active lever press response for sucrose reinforcement, and received similar total numbers of CS-sucrose pairings (data not shown; 250 pairings; $F<1$ ). Moreover, the number of CS exposures received during the reactivation session was not different between the contingently reactivated groups (Fig. 2).

The present results indicate that the memory for an appetitive CS-sucrose association, when acquired instrumentally, can be reactivated successfully only if the CS is again presented contingent upon the instrumental response in order to induce the reconsolidation process. A reactivation-dependent amnesia was observed only when the NMDA re- 


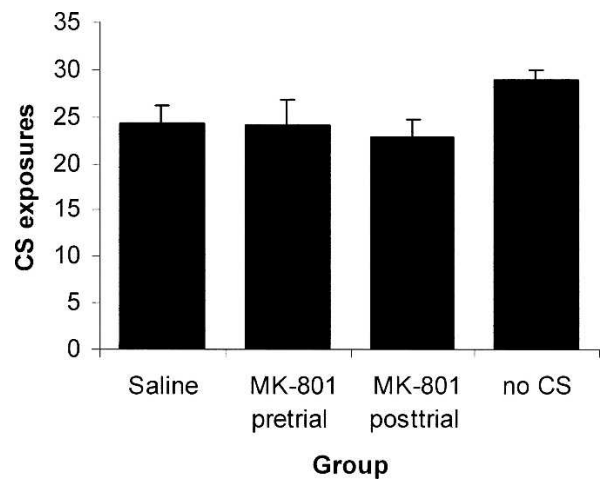

Figure 2. Number of conditioned stimulus (CS) re-exposures during the contingent memory reactivation session. All groups received similar numbers of CS presentations $\left(F_{(3,28)}=2.18, P>0.11\right)$. Moreover, none of the groups tested in the presence of the CS (Saline, MK-801 pre-trial, and MK-801 post-trial) differed significantly from the rats re-exposed noncontingently to the CS 24 times (one-sample t-tests; $t_{(7,0.05)} \mathrm{s}<0.62$, Ps $>0.55)$. Data presented as mean + SEM.

ceptor antagonist MK-801 was injected prior to response contingent re-exposure to the CS. NMDA receptor signaling has previously been demonstrated to be critically required for the reconsolidation of both aversive and appetitive memories (Przybyslawski and Sara 1997; Suzuki et al. 2004; Torras-Garcia et al. 2005; Akirav and Maroun 2006; Lee et al. 2006b; Lee and Everitt 2008). In all of these studies, the presentation of the CS during memory reactivation took place in a manner similar to that experienced during training. In fear conditioning and an odor-reward associative procedure, the stimuli were presented passively at all times (Suzuki et al. 2004; Torras-Garcia et al. 2005; Lee et al. 2006b), and in both maze and object recognition tasks the reactivation session was identical to the training sessions (Przybyslawski and Sara 1997; Akirav and Maroun 2006). Finally, in an acquisition of a new response with conditioned reinforcement procedure, the CS was always delivered contingent upon behavioral responding (Lee and Everitt 2008). Thus, the present data are unique in using a procedure in which the response contingency of CS presentation is different at reactivation to that during training.

It is possible that the observed lack of amnesia following noncontingent CS presentation relates not to effects of response contingency, but simply to the removal of the levers during the reactivation session. This might alter the experimental context sufficiently that CS presentation, no matter how it is achieved, does not effectively reactivate the memory. However, such contextual influences have not been observed in other paradigms. For example, re-exposure to the conditioned odor in the home cage was sufficient to induce NMDA receptor-dependent reconsolidation in another reward-related task (Torras-Garcia et al. 2005).

Neurotransmission events related to stimulus exposure previously have been shown to be influenced by the manner of CS presentation (Ito et al. 2000, 2002). A cocaine-associated CS elicited dopamine release in the nucleus accumbens core only when presented noncontingently (Ito et al. 2000), and in the dorsal striatum only when delivered contingent upon drug seeking (Ito et al. 2002). Therefore, it is conceivable that such differential responses are related to the specific ability of contingent CS presentation to reactivate previously acquired memories.

The present results are somewhat inconsistent with our previous data using a relapse to cocaine seeking procedure, in which noncontingent presentations of a cocaine-associated CS were effective in reactivating the drug memory, rendering it vulnerable to disruption through the intracerebral infusion of antisense oligodeoxynucleotides targeting the immediate-early gene Zif268 (Lee et al. 2006a). Thus, with CS-cocaine memories, the contingency of stimulus presentation did not appear to be an important variable (Lee et al. 2005, 2006a). However, it must be noted that the cocaine CS was presented 30 times noncontingently (Lee et al. 2006a), compared with the 24 presentations of the sucrose CS in the present study, and so it remains possible that a greater number of noncontingent CS presentations would have been sufficient to reactivate the sucrose memory. Nevertheless, it remains the case that CS presentation was more effective in reactivating the memory when it occurred response-contingently. It is also possible that the well-learned drug-associated memory, arising from hundreds of pairings of the CS with selfadministered intravenous infusions of cocaine (Lee et al. 2006a), is more easily reactivated than the less intensively trained natural reward-related memory here, and that this contributes to the persistent maladaptive effects of drug memories on addictive behavior. This may, in part, explain the inconsistent findings from studies employing a conditioned place preference procedure, in which there are limited numbers of CS-drug pairings, and different reactivation requirements have been reported in order to observe reconsolidation impairments (Miller and Marshall 2005; Valjent et al. 2006; Yim et al. 2006).

An alternative explanation for the different effects of sucrose versus cocaine memory reactivation is that the response contingency-dependence observed here is specifically related to the use of NMDA receptor antagonism as the amnestic treatment. It has been shown that the blockade of NR2B-containing NMDA receptors in the amygdala prevents the reactivation of a conditioned fear memory, thereby protecting it from the amnestic effects of protein synthesis inhibition (Ben Mamou et al. 2006). Therefore, it is possible that MK-801 administration in fact prevented the reactivation of the CS-sucrose memory by noncontingent CS presentation. Thus, glutamatergic signaling at NMDA receptors may be necessary to reactivate a CS-sucrose memory, but only when the CS is presented passively. This hypothesis would predict that in the noncontingent condition, MK-801 would protect an acquired CS-sucrose memory from reactivation-dependent amnesia effected by some other amnestic agent.

While we have discussed the potential contingency- and NMDA receptor-dependence of memory "reactivation," it is perhaps more accurate to term the process memory "destabilization." Amnestic agents such as MK-801 and protein synthesis inhibitors impair memory not directly, but rather through the disruption of the neurobiological processes that are necessary to stabilize or re-stabilize a memory. Thus, by implication, it is the reactivation process itself that actively destabilizes the memory. This reactivation or destabilization process is clearly an important focus of future research, especially in relation to the potential clinical targeting of reconsolidation in therapeutic settings (Ben Mamou et al. 2006). The present data indicate that the manner in which salient memory-evoking stimuli are presented is an important consideration when attempting to induce reactivation-dependent amnesia.

\section{Acknowledgments}

This work was supported by a grant from the UK Medical Research Council (program grant no. 9536855) and was conducted within the MRC/Wellcome Trust Behavioural and Clinical Neuroscience Institute.

\section{References}

Akirav, I. and Maroun, M. 2006. Ventromedial prefrontal cortex is obligatory for consolidation and reconsolidation of object recognition memory. Cereb. Cortex 16: 1759-1765. 
Alberini, C.M. 2005. Mechanisms of memory stabilization: Are consolidation and reconsolidation similar or distinct processes? Trends Neurosci. 28: 51-56.

Ben Mamou, C., Gamache, K., and Nader, K. 2006. NMDA receptors are critical for unleashing consolidated auditory fear memories. Nat. Neurosci. 9: 1237-1239.

Brunet, A., Orr, S.P., Tremblay, J., Robertson, K., Nader, K., and Pitman, R.K. 2007. Effect of post-retrieval propranolol on psychophysiologic responding during subsequent script-driven traumatic imagery in post-traumatic stress disorder. J. Psychiatr. Res. 42: 503-506.

Debiec, J. and Altemus, M. 2006. Toward a new treatment for traumatic memories. Cerebrum 2-11.

Debiec, J., Doyere, V., Nader, K., and LeDoux, J.E. 2006. Directly reactivated, but not indirectly reactivated, memories undergo reconsolidation in the amygdala. Proc. Natl. Acad. Sci. 103: $3428-3433$.

Dudai, Y. 2004. The neurobiology of consolidations, or, how stable is the engram? Annu. Rev. Psychol. 55: 51-86.

Hellemans, K.G.C., Dickinson, A., and Everitt, B.J. 2006. Motivational control of heroin seeking by conditioned stimuli associated with withdrawal and heroin taking by rats. Behav. Neurosci. 120: 103-114.

Ito, R., Dalley, J.W., Howes, S.R., Robbins, T.W., and Everitt, B.J. 2000. Dissociation in conditioned dopamine release in the nucleus accumbens core and shell in response to cocaine cues and during cocaine-seeking behavior in rats. J. Neurosci. 20: 7489-7495.

Ito, R., Dalley, J.W., Robbins, T.W., and Everitt, B.J. 2002. Dopamine release in the dorsal striatum during cocaine-seeking behavior under the control of a drug-associated cue. J. Neurosci. 22: 6247-6253.

Lee, J.L. and Everitt, B.J. 2008. Appetitive memory reconsolidation depends upon NMDA receptor-mediated neurotransmission. Neurobiol. Learn. Mem. doi: 10.1016/j.nlm.2008.02.004.

Lee, J.L.C., Di Ciano, P., Thomas, K.L., and Everitt, B.J. 2005. Disrupting reconsolidation of drug memories reduces cocaine seeking behavior. Neuron 47: 795-801.

Lee, J.L.C., Milton, A.L., and Everitt, B.J. 2006a. Cue-induced cocaine seeking and relapse are reduced by disruption of drug memory reconsolidation. J. Neurosci. 26: 5881-5887.

Lee, J.L.C., Milton, A.L., and Everitt, B.J. 2006b. Reconsolidation and extinction of conditioned fear: Inhibition and potentiation. $J$. Neurosci. 26: 10051-10056.

Miller, C.A. and Marshall, J.F. 2005. Molecular substrates for retrieval and reconsolidation of cocaine-associated contextual memory. Neuron 47: 873-884.

Nader, K. 2003. Memory traces unbound. Trends Neurosci. 26: 65-72.

Przybyslawski, J. and Sara, S.J. 1997. Reconsolidation of memory after its reactivation. Behav. Brain Res. 84: 241-246.

Suzuki, A., Josselyn, S.A., Frankland, P.W., Masushige, S., Silva, A.J., and Kida, S. 2004. Memory reconsolidation and extinction have distinct temporal and biochemical signatures. J. Neurosci. 24: 4787-4795.

Torras-Garcia, M., Lelong, J., Tronel, S., and Sara, S.J. 2005. Reconsolidation after remembering an odor-reward association requires NMDA receptors. Learn. Mem. 12: 18-22.

Valjent, E., Corbille, A.G., Bertran-Gonzalez, J., Herve, D., and Girault, J.A. 2006. Inhibition of ERK pathway or protein synthesis during reexposure to drugs of abuse erases previously learned place preference. Proc. Natl. Acad. Sci. 103: 2932-2937.

Yim, A.J., Moraes, C.R., Ferreira, T.L., and Oliveira, M.G. 2006. Protein synthesis inhibition in the basolateral amygdala following retrieval does not impair expression of morphine-associated conditioned place preference. Behav. Brain Res. 171: 162-169.

Received February 22, 2008; accepted in revised form April 7, 2008. 


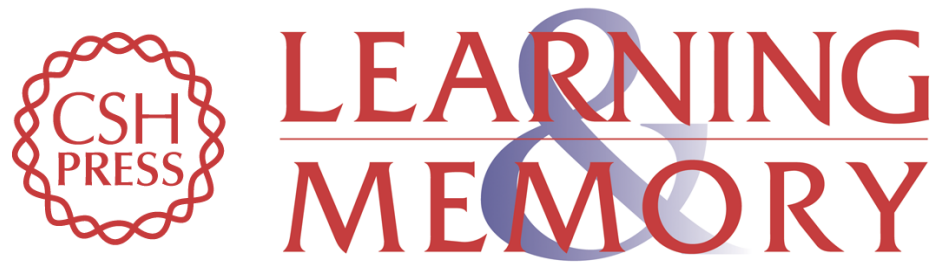

\section{Reactivation-dependent amnesia for appetitive memories is determined by the contingency of stimulus presentation}

Jonathan L.C. Lee and Barry J. Everitt

Learn. Mem. 2008, 15:

Access the most recent version at doi:10.1101//m.976108

References This article cites 19 articles, 8 of which can be accessed free at:

http://learnmem.cshlp.org/content/15/6/390.full.html\#ref-list-1

License

Email Alerting Receive free email alerts when new articles cite this article - sign up in the box at the Service top right corner of the article or click here. 